\title{
Ensuring Racial Equity in Pregnancy Care During the COVID-19 Pandemic and Beyond
}

\author{
Ayotomiwa Ojo ${ }^{1}$ (D) Adam L. Beckman ${ }^{1} \cdot$ Amber Weiseth $^{2} \cdot$ Neel Shah $^{1,2,3}$
}

Accepted: 13 June 2021 / Published online: 28 June 2021

(c) The Author(s), under exclusive licence to Springer Science+Business Media, LLC, part of Springer Nature 2021

\begin{abstract}
Background The COVID-19 pandemic provoked sweeping changes in practice to care for pregnant and birthing people, and highlighted inequities that threaten to exacerbate racial disparities in maternal outcomes. Moreover, social distancing measures have made it harder for pregnant people to access support.

Assessment Prioritizing widespread access to COVID-19 testing and vaccination for pregnant people is critical to ensuring they receive safe and equitable care. Transparency in reporting outcomes including race and pregnancy status is key. Expanding telemedicine services to provide mental healthcare and labor support is necessary to maintain access to critical social networks. Additionally, resources must be allocated to pregnant people with complex social needs and are the most vulnerable.

Conclusion Policy centered on maintaining equity and agency in the care of pregnant people is imperative now and should continue as the standard moving forward to narrow racial disparities in maternal health outcomes.
\end{abstract}

Keywords Health equity $\cdot$ COVID- $19 \cdot$ Telemedicine $\cdot$ Labor support

\section{Significance Statement}

What is already known? The COVID-19 pandemic has forced healthcare systems to rapidly modify care delivery, decreasing birthing people's agency and access to health services and support. Before the pandemic, Black and Native women experienced higher rates of maternal mortality than non-Hispanic white women, and the restrictions imposed by the pandemic threatens to exacerbate their risks.

What this article adds? To address racial disparities in maternal care, policy that promotes equitable access to holistic support in pregnancy care is essential. We outline recommendations to increase access to medical care and social support for pregnant patients, particularly for the most vulnerable.

Ayotomiwa Ojo

Ayotomiwa_ojo@hms.harvard.edu

1 Harvard Medical School, 25 Shattuck Street, Boston, MA 02115, USA

2 Ariadne Labs, Brigham \& Women's Hospital, Harvard T.H. Chan School of Public Health, Boston, MA, USA

3 Beth Israel Deaconess Medical Center, Boston, MA, USA
The COVID-19 pandemic has magnified existing gender and racial inequities across the world. In the United States, this has notably amplified the risks to pregnant Black and Native women, who are significantly more likely to die due to pregnancy-related causes than non-Hispanic white women (Petersen et al., 2019). COVID-19 infection during pregnancy may increase the likelihood of preterm birth and intensive care admission or invasive ventilation (Centers for Disease Control \& Prevention, 2020). Pregnant people are left vulnerable by both the physical and social sequelae of this global pandemic.

According to some maternity care experts, non-standardized and reactive decisions about pregnancy care early in the pandemic overlooked pregnant people's agency or control of their care and their need for their support system to the detriment of already marginalized communities (Niles et al., 2020). Anecdotally, when symptomatic pregnant people are told by their providers to self-isolate, they feel dismissed. When hospital visitation restrictions are imposed, they feel abandoned. When scarce health services are rationed, they feel condemned. Improving trust between health systems and the communities they serve will be critical to providing good care (Bauchner, 2019). And a sharp focus on equity 
is necessary in implementing any actions that address the wellbeing of pregnant people and their families.

\section{Reporting and Providing Access to COVID-19 Testing and Vaccination}

First, widespread access to COVID-19 testing and vaccination for pregnant people with reporting on demographic data is essential. Already, low-income communities and communities of color face longer wait times and fewer options to access testing because of disparities in testing resource allocation (Kim et al., 2020). Testing site distribution and capacity should reflect goals for equity where available supplies match the severity of COVID-19 infection rates within communities. Similarly, uncoordinated vaccination efforts across the country focused on vaccinating as many people as possible without consideration of equity will leave marginalized people behind, including those who are pregnant. ACOG recommends that pregnant people should have access to the COVID-19 vaccine whenever they meet priority group criteria for vaccinations (ACOG, 2020).

Already, low-income communities of color have been disproportionately affected by COVID-19 across the United States (Cineas, 2020), yet information remains hidden about who is getting tested and vaccinated. For instance, as of February 7,2021 , only three states reported testing rates by race (Johns Hopkins Coronavirus Resource Center, 2020.). Thirty-four states are documenting vaccination data with race, however, early reports all show that Black and Latinx people are being vaccinated at rates substantively below their share of Covid-19 cases and deaths (Ndugga et al., 2021). All states should require testing and vaccination data to document race, auditing equitable access to testing and hospital resources (Krieger et al., 2020). To quell the already disproportionate impact of COVID-19 among marginalized people it is necessary to prioritize vulnerable communities for vaccination, particularly those for whom social isolation is not possible and potentially dangerous.

\section{Accessing Routine Inpatient Labor and Delivery Care}

At times of peak capacity, some hospitals closed their birthing units to make more ICU beds available or open new field hospitals (Johnson \& Forster, 2020), increasing interest and access to birthing centers. With the potential for increased deliveries at alternative birthing centers, coordination between obstetrics providers-including obstetricians, midwives, and nurses-is central to achieving favorable outcomes for mothers and infants. In the U.S., new Center for Medicare and Medicaid Services (CMS) waivers allow alternative facilities to be reimbursed for deliveries, thereby reducing financial risk to health systems and enabling more options for patients. These changes may also increase the capability to center birth settings in the communities pregnant people live in, and help close an existing divide between many health systems and the communities they serve.

\section{Access to Social Support During Labor and Beyond}

Strict, although necessary, hospital visitation policies and skeleton staffing often mean less labor support. For example, in some cases, doulas and additional family members are often no longer allowed into birthing rooms, even though their presence is known to improve outcomes (Bohren et al., 2017). Moreover, clinicians masked by full personal protective equipment make communicating challenging and threatens to further isolate patients in their birthing process. As pregnant women anxiously anticipate their delivery, labor units can provide technology, such as e-doula services (DONA, 2020), to support alternative birthing plans that allow patients to virtually interact with their support people.

In all care settings, we should recognize the barriers that birthing people face in maintaining agency throughout their pregnancy and postpartum experience, particularly for people of color, and the role of having a birth support person of choice in mitigating racial disparities. Clinicians should be trained to mitigate implicit bias, but this alone will not be enough. Continuous labor support promotes favorable maternal outcomes, such as decreased cesarean sections and decreased negative feelings about the child birthing experience (Bohren et al., 2017). Ensuring access to this essential component of care for vulnerable patients has the potential to narrow the racial gaps in maternal outcomes. Measures should be taken to provide safe access to social support, including prioritizing protective equipment availability and rapid testing on labor and delivery units. Policymakers can facilitate such connections by reimbursing professional labor support. Although Medicaid reimbursement of doula services has demonstrated better maternal-infant outcomes and potential for cost savings in the United States, only two states have passed legislation for Medicaid reimbursement of doula services (Kozhimannil et al., 2013; Strauss et al., 2016). Adopting this policy nationwide has the potential to prevent excessive costs, and promote maternal wellbeing, amid unprecedented and unpredictable times. In response to the pandemic, CMS broadened access to telemedicine by removing restrictions on reimbursement to essential non-physician healthcare providers (Mehortra et al., 2020). Doulas are a valuable support system to patients and contribute to quality clinical care. This should be acknowledged 
through insurance policies that reimburse their services, whether in-person or virtual.

\section{Mental Health Postpartum}

Devoting adequate resources and attention to mental health and social support throughout the prenatal and postpartum period is critical. Postpartum depression affects nearly $15 \%$ of new mothers (Pearlstein et al., 2009), a challenge that is likely to be exacerbated by social distancing. Lack of social support increases the likelihood of postpartum depressive symptoms, particularly for women in low-income households (Surkan et al., 2006). Isolation from extended family and other supports makes parents of newborns who were already at risk for depression or other mental illness even more vulnerable.

While in-person appointments provide time to assess mental health, their absence necessitates alternative solutions. Health systems can carefully coordinate access to telemedicine mental health care for postpartum patients. Telehealth platforms should innovate beyond 1-on-1 visits to facilitate virtual support groups and classes for new parents. To provide equitable, high quality care via telemedicine, insurers should be required to reimburse all virtual care under telehealth parity law.

\section{Access to Critical Outpatient Services}

Enabling access to necessary contraceptive and other outpatient services is critical. Some aspects of prenatal and postpartum care cannot be sufficiently replaced by virtual care. For example, long-acting reversible contraception (LARC) is harder to access. Furthermore, policymakers in some U.S. states have labeled pregnancy termination services as non-essential. Eliminating access to critical services will result in spikes of unintended pregnancy and limit agency. As systems increasingly deliver home-based care, such as home hospitalizations (Emanuel \& Navathe, 2020) certain OB-GYN services may be appropriate for the home setting. Increasing access to medication-assisted abortion and exploring innovative methods of LARC placement outside of hospital facilities should be considered.

\section{Meeting Complex Social Needs}

Meeting the economic, housing, food, and other social needs for pregnant people is germane to their health. As unemployment rates rapidly increase, pregnant people may be at elevated risk of economic instability given the new costs of growing a family. Patients in the process of social services coordination or those newly identified as requiring services may be lost to follow up while the system is overwhelmed and transitioning to new models of care delivery. Bolstering social work and patient coordination services are crucial to ensuring that patients' socioeconomic needs are addressed. Pregnant and postpartum patients should be prioritized in the allocation of social services to ensure housing, food, and income support.

Special attention to the most vulnerable and disenfranchised patients is needed. Domestic violence is a leading killer of pregnant people. Virtual care creates several specific challenges-not everyone has the necessary technology or privacy for medical consultation at home, and not all homes are safe (Gupta \& Stahl, 2020). When patients seek in-person care, extra efforts are needed to screen for domestic violence and connect affected persons with appropriate resources. This may be the only opening for intervention.

Additionally, pregnant people who are detained in U.S Immigrations and Customs Enforcement (ICE) facilities or are incarcerated are an extremely vulnerable group at risk for COVID-19 infection (Lang, 2020; Lopez, 2020). Shelters and holding facilities are at high risk of uncontrollable outbreaks. Some states are expanding eligibility for early release among federal inmates to prevent further burdening prison medical facilities and hospitals (Benner, 2020). Pregnant people should be prioritized and made eligible for early release. Furthermore, ensuring their housing security after release by partnering with community organizations experienced with safely transitioning the formerly incarcerated is crucial.

\section{Conclusion}

This pandemic is requiring health systems to rapidly innovate and modify care delivery to keep their communities safe. Adaptations in obstetric care to increase holistic support to the most vulnerable through the postpartum period, are relevant outside of the context of a pandemic. Expanding coverage for labor support and mental health services and tailoring care for low-income people and people of color beyond the pandemic supports more equitable access to vital services. Policy centered on equity and agency in the care of pregnant people is imperative now but should continue as the standard moving forward to narrow the disparities in maternal outcomes. Services that were essential before the pandemic remain essential now. We need to be innovative in our public policies and in the design of our services to make sure these services are not deprioritized. Whether under the guise of a pandemic or not, people will continue to have babies. They deserve safety, dignity, and support. 


\section{Declarations}

Conflict of interest The authors report no conflicts of interest.

\section{References}

ACOG. (2020) Vaccinating pregnant and lactating patients against COVID-19. Retrieved February 24, 2021, from https://www.acog. org/clinical/clinical-guidance/practice-advisory/articles/2020/12/ vaccinating-pregnant-and-lactating-patients-against-covid-19

Bauchner, H. (2019). Trust in health care. JAMA, 321(6), 547. https:// doi.org/10.1001/jama.2018.20795

Benner, K. (2020). Barr expands early release of inmates at prisons seeing more coronavirus cases-The New York Times. Retrieved from https://www.nytimes.com/2020/04/03/us/politics/barr-coron avirus-prisons-release.html

Bohren, M. A., Hofmeyr, G. J., Sakala, C., Fukuzawa, R. K., \& Cuthbert, A. (2017). Continuous support for women during childbirth. Cochrane database of systematic reviews. Wiley. https://doi.org/ 10.1002/14651858.CD003766.pub6

CDC (2020)Pregnancy and Breastfeeding IRetrieved. April 26, 2020, from https://www.cdc.gov/coronavirus/2019-ncov/need-extraprecautions/pregnancy-breastfeeding.html?CDC_AA_refVal= https\%3A\%2F\%2Fwww.cdc.gov\%2Fcoronavirus\%2F2019-ncov\% 2Fprepare\%2Fpregnancy-breastfeeding.html

Cineas, F. (2020). Coronavirus is disproportionately taking black lives - Vox. Retrieved from https://www.vox.com/identities/2020/4/7/ 21211849/coronavirus-black-americans

Emanuel, E. J., \& Navathe, A. S. (2020). Opinion. How the pandemic can improve America's Health Care System-The New York Times. Retrieved from https://www.nytimes.com/2020/04/14/ opinion/coronavirus-hospitals.html

Haridasani Gupta, A., \& Stahl, A. (2020). For abused women, a pandemic lockdown holds dangers of its own-The New York Times. Retrieved from https://www.nytimes.com/2020/03/24/us/coron avirus-lockdown-domestic-violence.html

Johnson, C. K., \& Forster, N. (2020). US hospitals rush to find beds for surge of virus patients-ABC News. Retrieved from https://abcne ws.go.com/Health/wireStory/us-hospitals-rush-find-beds-surgevirus-patients-69806047

Kim, S. R., Vann, M., Bronner, L., \& Manthey, G. (2020, July 22). Which cities have the biggest racial gaps in COVID-19 testing access? I FiveThirtyEight.

Kozhimannil, K. B., Hardeman, R. R., Attanasio, L. B., Blauer-Peterson, C., \& O'Brien, M. (2013). Doula care, birth outcomes, and costs among medicaid beneficiaries. American Journal of Public Health, 103(4), e113. https://doi.org/10.2105/AJPH.2012.301201

Krieger, N., Gonsalves, G., Bassett, M. T., Hanage, W., \& Krumholz, H. M. (2020). The fierce urgency of now: Closing glaring gaps in US surveillance data On COVID-19|Health Affairs. Retrieved from https://www.healthaffairs.org/do/10.1377/hblog20200414. 238084/full/
Lang, M. J. (2020). ICE detainees seek release amid coronavirus fears-The Washington Post. Retrieved from https://www.washi ngtonpost.com/local/ice-coronavirus-detention-centers-release/ 2020/04/08/f4dcaef8-74ee-11ea-87da-77a8136c1a6d_story.html

Lopez, G. (2020). Coronavirus in jails or prisons could turn into a nightmare-Vox. Retrieved from https://www.vox.com/policyand-politics/2020/3/17/21181515/coronavirus-covid-19-jailsprisons-mass-incarceration

Mehrotra, A., Wang, B., \& Snyder, G. (2020). Telemedicine: What should the post-pandemic regulatory and payment landscape look like? ICommonwealth Fund. Retrieved August 5, 2020, from https://www.commonwealthfund.org/publications/issue-briefs/ 2020/aug/telemedicine-post-pandemic-regulation

Ndugga, N., Pham, O., Hill, L., Artiga, S., \& Mengistu, S. (2021, February 18). Latest data on COVID-19 vaccinations race/ ethnicity|KFF. Retrieved from https://www.kff.org/coronaviruscovid-19/issue-brief/latest-data-on-covid-19-vaccinations-raceethnicity/

Niles, P. M., Asiodu, I. V., Crear-Perry, J., Julian, Z., Lyndon, A., McLemore, M. R., Planey, A. M., Scott, K. A., \& Vedam, S. (2020). Reflecting on Equity in perinatal care during a pandemic. Health equity (Vol. 4, pp. 330-333). Mary Ann Liebert Inc. https://doi.org/10.1089/heq.2020.0022

Pearlstein, T., Howard, M., Salisbury, A., \& Zlotnick, C. (2009). Postpartum depression. American Journal of Obstetrics and Gynecology, 200(4), 357-364. https://doi.org/10.1016/j.ajog.2008.11.033

Petersen, E. E., Davis, N. L., Goodman, D., Cox, S., Syverson, C., Seed, K., Shapiro-Mendoza, C., Callaghan, W. M., \& Barfield, W. (2019). Racial/ethnic disparities in pregnancy-related deathsUnited States, 2007-2016. MMWR Morbidity and Mortality Weekly Report, 68(35), 762-765. https://doi.org/10.15585/mmwr. $\mathrm{mm} 6835 \mathrm{a} 3$

Strauss, N., Sakala, C., \& Corry, M. P. (2016). Overdue: Medicaid and private insurance coverage of doula care to strengthen maternal and infant health. The Journal of Perinatal Education, 25(3), 145-149. https://doi.org/10.1891/1058-1243.25.3.145

State Testing Data by Race-Johns Hopkins Coronavirus Resource Center. (2020). Retrieved May 28, 2020, from https://coronavirus. jhu.edu/data/racial-data-transparency

Surkan, P. J., Peterson, K. E., Hughes, M. D., \& Gottlieb, B. R. (2006). The role of social networks and support in postpartum women's depression: A multiethnic urban sample. Maternal and Child Health Journal, 10(4), 375-383. https://doi.org/10.1007/ s10995-005-0056-9

Sutton, D., Fuchs, K., D'Alton, M., \& Goffman, D. (2020). Universal screening for SARS-CoV-2 in women admitted for delivery. The New England Journal of Medicine. https://doi.org/10.1056/ NEJMc2009316

Publisher's Note Springer Nature remains neutral with regard to jurisdictional claims in published maps and institutional affiliations. 